\title{
Explore the Intention of Tourists of Visiting Colorful Village- A Case Study of Jingpu Colorful Village "Cat World"
}

\author{
Kuo-Chung Huang \\ Professor \\ Department of Business Administration \\ Nanhua University, Chiayi \\ Taiwan \\ Mei-Li Yang \\ Ph.D. Student \\ Department of Business Administration \\ Nanhua University, Chiayi \\ Taiwan
}

\begin{abstract}
This paper applies the theory of planned behavior to study the tourists' intentions of visiting the Jingpu Colorful Village "Cat World". The questionnaire was distributed and collected in Jingpu village based on a purposive sampling method. Empirical results reveal that the tourists' attitudes, subjective norms, and perceived behavioral control had positive effect on their intention respectively. Perceived behavioral control has the most significant impact on intention. The construct of attitudes has a complete mediation effect on the subjective norms to the intention. Perceived behavioral control has a partial mediation effect on construct of subjective norms to the intention. According to semi-structure questions result, convenient and friendly hardware as well as travel itinerary with local industrial features help sustainable tourism development of the village.
\end{abstract}

Keywords: Comprehensive Community Development, Jingpu Colorful Village, Cat World, Theory of Planned Behavior, Intention.

\section{Introduction}

In recent years, Taiwan has been promoting comprehensive community development. Many communities have created eye-catching sightseeing spots through artistic creation. Min-hsiung township is located in mid-northern Chiayi county and was called "Da-Mao" before Japanese people get rule of Taiwan. "Da-Mao" originated from the name of the Pingpu Tribe "Dovaha", which Hoklo Taiwanese transliterated as "Da-Mao" (Mao means cat). Therefore, the Jingpu Village Community Development Association promotes cat-themed paintings and invited community painter Zung-Lin Tan to create the "Cat World" colored drawings on the walls of old buildings in the village. The painter used interactive composition and contextual paintings to present different styles and interesting cats, which have also given a new vitality to the old houses as well as the community ofJingpu village. Meanwhile, they have attracted tourists successfully and made the aging community become lively and energetic.

Many painted villages in Taiwan are facing decline of tourists number after the craze right after the completion of paintings. In the past few years, the number of tourists visiting the Jingpu Colorful Village "Cat World" has also been declining. How to promote the village paintings has become an important issue to the Jingpu Village Community Development Association and all the villagers. Many scholars have pointed out that trying to understand the intentions of visit, as well as providing friendly and convenient services, can attract and maintain existing customers and develop potential ones. At the same time, it affects visitors' willingness to revisit or recommend the benefits to others (Brady \& Cronin, 2001; Kim, Ferrin, \& Rao, 2009).

The theory of planned behavior proposed by Ajzen (1985) is a theory derived from rational behavior theory and mainly used to explain and predict people's behavior. The theory of planned behavior indicated that the intentions were influenced by attitudes, subjective norms, and perceived behavioral control. 
The purpose of this study based on the theory of planned behavior is to investigate the tourists' intention of visiting the Jingpu Colorful Village "Cat Word" in Chai-yi. The research results could help the Jingpu Village Community Development Association planning the comprehensive community development in the future, and reduce obstruction of visiting, furthermore help pursuing sustainable tourism development of the village.

\section{Literature Review}

\subsection{Comprehensive Community Development}

According to the White Paper on Cultural Affairs report by Department of Council for Cultural Affairs, Executive Yuan (2004), the authority present the comprehensive community development topic and indicate the purpose of the policy. The first stage, in order to raise peoples' community awareness, to regain people's sense of identity in their own communities, and to jointly improve the quality of community life, the government needs to encourage the residents to participate in comprehensive community development. The second stage of the comprehensive community development emphasize concept cultivation and training to raise life quality and encourage more residents to concern their hometown through cultural life circuit (Wang, 2016). Ministry of Culture (2015) present the third stage (2016-2021) of community empowerment to establish cultural citizen society and strike a balance culture resource of urban-rural gap. Many communities have begun the plan to promote comprehensive community development, and political support from the government becomes an important thrust for community development in Taiwan. Many scholars have indicated that the purpose of comprehensive community development is to promote and to improve local cultural environment of communities. Therefore, it is necessary to formulate and implement strategies according to the characteristics of communities themselves, such as improving the living environment of the communities, preserving local cultural or historical materials like monuments, or promoting community arts and cultural activities. In addition to local community development association, it is also necessary for the residents and other organizations to participate (Chang, 2012; Chang, 2015; Chao, 2015; Hsieh, 2017). Through the participation of the residents, the common living space and the vitality of the community might be improved. In additional, the modification space attract tourists' visiting and create business opportunity to local.

\subsection{Jingpu Colorful Village "Cat Word"}

Jingpu village is a typical rural village. The residents depend mainly on farming for their livelihoods, so the community is a traditional rural settlement. Jingpu has been developing for more than 100 years. As time went on, many buildings have been rebuilt into modern cement buildings. However, there are still many traditional courtyard houses, and earth horns or abandoned pig houses still exist in the community. The preservation of the quaint beauties of the community is significant. However, some abandoned pig houses, ancient urns, and soil barns have gradually become idle and dirty in the community because of obsolescence or ruination. Through the community wall paintings, the community's environmental beauty will be enhanced, the residents will feel and recognize the beauty of their own community, and then achieve community consciousness. (Jingpu Community Development Association, 2014)

\subsection{Theory of Planned Behavior}

The theory of planned behavior indicated that determinant behavior is one's intention to engage in that behavior. The intention is determined by three constructs: attitudes toward the behavior, subjective norms, and perceived behavioral control (Ajzen, 1991). As a general rule, the more favorable the attitudes and subjective norms, and the greater the perceived control, the stronger should be the person's intention to perform the behavior in question (Ajzen, 2006). Based on theory of planned behavior, Dai, Wang, Kao, \& Lee (2012) collected 222 questionnaires with 207 valid data which apparently convey perceived behavior control was the most important factor in determining intentions to water recreation. Hsieh, Huang, \& Hsu (2017) totally collected 400 questionnaires including 263 valid with the effective rate of $65.75 \%$, found the attitudes and perceived behavior control of tourists had a significant impact on behavioral intention. In this study, the construct of "attitudes" is defined as evaluating the cognition of the tourists about the feelings of visiting colorful village, and "subjective norms" is defined as examining how the tourists' family, relatives, friends and others influence on their visits to village paintings locations. And "perceived behavioral control" is defined as observing how well the tourists have cognition of their ability to handle their time, health condition, financial ability and transportation. 


\section{Methodology}

\subsection{Research Model and Hypotheses}

In this study, exploring the tourists' behavior and intention, the framework is considered and builds basically.

\section{Figure 1 shows the research model considered}

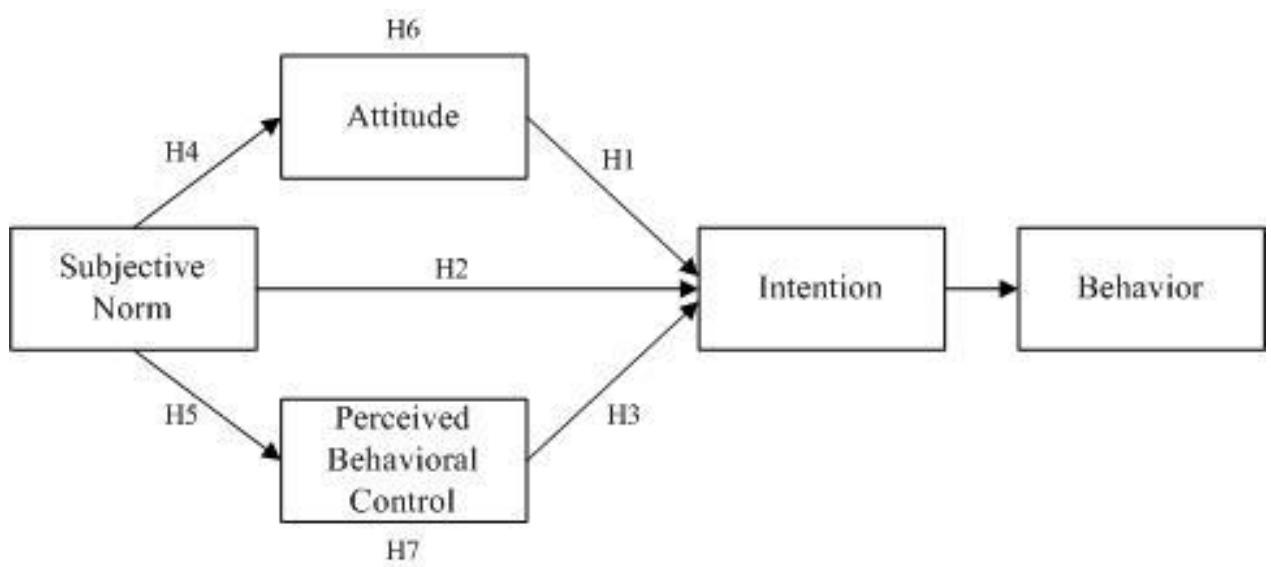

According to the framework, seven hypotheses considered are listed as follows:

H1. Attitudes of the tourists have played a positive role in affecting the tourists' intention to visit the Jingpu Colorful Village "Cat World".

H2. Subjective norms of the tourists have played a positive role in affecting the tourists' intention to visit the Jingpu Colorful Village "Cat World".

H3. Perceived behavioral controls of the tourists' have played a positive role in affecting the tourists' intention to visit the Jingpu Colorful Village "Cat World".

H4. Subjective norms of the tourists have played a positive role in affecting the tourists' attitudes.

H5. Subjective norms of the tourists have played a positive role in affecting the tourists' perceived behavioral control.

H6. Attitudes of the tourists have a mediation effect between tourists' subjective norms and their intention.

H7. Perceived behavioral control of the tourists have a mediation effect between tourists' subjective norms and the intention.

\subsection{Questionnaire Design}

In this study, based on the relevant literature and suggestion from three experienced people, a former director general of Jingpu Village Community Development Association, a local elder, and a professional scholar, we tried to find multiple tourism dimensions. The data collected has content validity. Four constructs were contained in this questionnaire. In the construct of "Attitudes", nine items were designed based on three studies (Ajzen, 1991; Blackwell, Engel \&Miniard, 2012; Hsu, Yeh \& Lin, 2012). In the construct of "Subjective norms", four items were designed based on the works done by some scholars (Ajzen, 1991; Schiffman \&Kanuk, 2000; Hsieh, Huang \& Hsu 2017). Five items in the construct of "Perceived behavior control" were designed based on four studies (Ajzen, 1991; Taylor \& Todd, 1995; Wang, 2016; Hsieh, Huang \&Hsu, 2017). Four items in the construct of "Intention" were designed based on the works by some scholars (Ajzen, 1991; Zeithaml, Berry \& Parasuraman, 1996; Kuo, 2008). The original questionnaire items apply the five-point Likert-type scale to indicate the tourists' agreement or disagreement with the items. The level of agreements in the Likert-type scale utilized responses from 1 to 5, where 1: Strongly Disagree; 2: Disagree; 3: Neither Agree nor Disagree; 4: Agree; 5: Strongly Agree. Meanwhile, the content of the questionnaire also included the source of the tourists, gender, age, marital status, education level, number of visits, and transportation of go back and forth, to collect the demographic information. Additionally, in order to understand the tourists' experience of visiting the painting villages and their suggestions to the Community Development Association. There were two semi-structure questions including "Have you visited other painting villages in Taiwan in addition to Jingpu Colorful Village "Cat World" and "Your advice to the Community Development Association". Before the questionnaires were distributed, a pilot study was conducted on March 30, 2018, when 50 tourists visiting the Jingpu Colorful Village "Cat World" were recruited to fill out questionnaires. The pilot survey of the questionnaire's draft helped ascertain the reliability and validity of the questionnaire. It also helped to remove ambiguous and inappropriate phrasing and wording. 
Therefore, the misunderstanding of wordings could be minimized and the credibility of the questionnaire data could be ascertained. In assessing the reliability of the questionnaire, the Cronbach's alpha was checked. According to Nunnally (1978), standard Cronbach's alpha should be greater than 0.5, with a coefficient alpha above 0.7 is preferred. Regarding to its satisfying internal consistency, in this study, the coefficient alpha of four construct were all above 0.7 , showing that the questionnaires had high reliability.

\subsection{Data Collection}

In this study, purposive sampling was employed and the questionnaires acquisition were distributed to collect opinions of tourists who visited the Jingpu Colorful Village "Cat World", from April 4 to 8, 2018. Altogether 220 tourists were recruited and finally 195 valid data were collected in this study.

\section{Analysis and Discussion}

\subsection{Demographic Information}

Altogether 195 valid data were collected in this study. 44.1 percent of the respondents were male and $75.9 \%$ were above 25 years old. 53.8 percent of the respondents were married and $66.7 \%$ educational level were above college. 84.6 percent responded that it was their first time to visit the Jingpu Colorful Village "Cat World" and $78.5 \%$ tourists drive by themselves, fewer came and left with public transportation tools. Detailed description statistics related to the respondents' characteristics were shown in Table 1.

Table 1. Demographic Information

\begin{tabular}{|c|c|c|c|}
\hline Item & Answering Options! & Frequency & Percent \\
\hline \multirow{2}{*}{ Gender } & Male & 86 & 44.1 \\
\hline & Female & 109 & 55.9 \\
\hline \multirow[t]{6}{*}{ Age } & $\leqq 24$ years & 47 & 24.1 \\
\hline & $25-34$ years & 45 & 23.1 \\
\hline & $35-44$ years & 38 & 19.5 \\
\hline & $45-54$ years & 30 & 15.4 \\
\hline & $55-64$ years & 19 & 9.7 \\
\hline & $\geqq 65$ years & 16 & 8.2 \\
\hline \multirow[t]{6}{*}{ Marital status } & Single & 90 & 46.2 \\
\hline & Married without children & 22 & 11.3 \\
\hline & Married with children & 71 & 36.4 \\
\hline & Divorce & 3 & 1.5 \\
\hline & Separated & 4 & 2.1 \\
\hline & Widowed & 5 & 2.6 \\
\hline \multirow[t]{5}{*}{ Education } & Elementary School & 5 & 2.6 \\
\hline & Jumior high School & 15 & 7.7 \\
\hline & Senior high School & 45 & 23.1 \\
\hline & College & 99 & 50.8 \\
\hline & Graduate School & 31 & 15.9 \\
\hline \multirow[t]{3}{*}{ Number of visits } & First time & 165 & 84.6 \\
\hline & $2-3$ times & 20 & 10.3 \\
\hline & Above 3 times & 10 & 5.1 \\
\hline \multirow{4}{*}{$\begin{array}{l}\text { Transportation of } \\
\text { go back and forth }\end{array}$} & Tour bus & 19 & 9.7 \\
\hline & Taxi & 6 & 3.1 \\
\hline & Drive by yourself & 153 & 78.5 \\
\hline & Others & 17 & 8.7 \\
\hline
\end{tabular}

\subsection{Factor Analysis and Reliability Analysis}

According to Table 2, it indicates that in this study, KMO values of attitudes, subjective norms, perceived behavioral control and intention are respectively given by $0.890,0.612,0.798$ and 0.789 , each construct's KMO value is greater than 0.5, and each construct's Bartlett's test of sphericity is significant, implying that the data are appropriate for factor analysis. 
Table 2. KMO Value and Bartlett's Test of Sphericity for Each Construct

\begin{tabular}{lllll}
\hline \multicolumn{1}{c}{ Construct } & KMO & \multicolumn{3}{c}{ Bartlett test of sphericity } \\
\cline { 3 - 6 } & value & Chi-square & df & Sig.(2-tailed) \\
\hline Attitudes & 0.890 & 773.229 & 36 & $0.000^{* * *}$ \\
Subjective Norms & 0.612 & 278.126 & 6 & $0.000^{* * *}$ \\
Perceived Behavioral Control & 0.798 & 267.433 & 10 & $0.000^{* * *}$ \\
Intention & 0.789 & 240.565 & 6 & $0.000^{* * *}$ \\
\hline p & &
\end{tabular}

The results of factor analysis for each construct were shown in Table 3. All the items' factor loadings are greater than 0.5 , with the percentage of variance respectively givenby $62.844 \%, 84.126 \%, 54.523 \%, 63.258 \%$. No item should be deleted. To examine there liability, all the values of Cronbach's alpha were greater than 0.7, implying a high degree of internal consistency.

Table 3. Results of Factor Analysis and Reliability Analysis

\begin{tabular}{lccc}
\hline \multicolumn{1}{c}{ Construct } & Factor Loading & $\begin{array}{c}\% \text { of } \\
\text { Varianc }\end{array}$ & Cronbach's alpha \\
\hline Attitudes & $0.501-0.823$ & 62.844 & 0.863 \\
Subjective Norms & $0.879-0.911$ & 84.126 & 0.754 \\
Perceived Behavioral Control & $0.656-0.796$ & 54.523 & 0.778 \\
Intention & $0.749-0.840$ & 63.258 & 0.804 \\
\hline
\end{tabular}

Related to subjective norms, the highest influenced factor is firstly that I accept my friend's recommendation, and secondly listen to my family's encouragement. Inaddition, television news or program report and Internet discussion affect whether rtourists want to visit the destination afterwards.

\subsection{Means Analysis}

Independent samples $\mathrm{T}$ test was adapted to gender, and for the other demographic items, one-way ANOVA with Scheffe's test of post-hoc comparisons were conducted, which indicate whether the demographic characteristics were very importantly different in statistics for each construct.

Table 4. Results of Means Analysis

\begin{tabular}{lcccc} 
Measure & Attitudes & $\begin{array}{c}\text { Subjective } \\
\text { Norms }\end{array}$ & $\begin{array}{c}\text { Perceived } \\
\text { Behavioral } \\
\text { control }\end{array}$ & $\begin{array}{c}\text { Behavioral } \\
\text { Intention }\end{array}$ \\
\hline Gender & $\mathrm{N}$ & $\mathrm{N}$ & $\mathrm{N}$ & $\mathrm{N}$ \\
Age & $\mathrm{N}$ & $\mathrm{N}$ & $\mathrm{N}$ & $\mathrm{N}$ \\
Marital status & $3>5$ & $\mathrm{~N}$ & $3>5$ & $\mathrm{~N}$ \\
Education level & $\mathrm{N}$ & $\mathrm{N}$ & $\mathrm{N}$ & $\mathrm{N}$ \\
Number of visits & $\mathrm{N}$ & $\mathrm{N}$ & $\mathrm{N}$ & $\mathrm{N}$ \\
Transportation of & go back and forth & S: & &
\end{tabular}

For understanding tourists' intention through Means Analysis, the results were shown in Table4. Among the six demographic items, the level of education was significantly related to attitudes and perceived behavioral control. For cognition and perceived behavioral control, the means of the tourists' education level who visit the Jingpu Colorful Village "Cat World", "senior high school" were greater than that of "graduate school". The tourists with education level of graduate school had higher ability to seek more exquisite itinerary tours resources than those of senior high school. Obviously, they were not satisfied with visiting the Jingpu Colorful Village "Cat World".

\subsection{Regression Analysis}

Based on linear regression, as the results showed in Table 5, the standardized regression coefficient of the construct of attitudes, subjective norms and perceived behavioral control to intention were $0.684,0.543$ and 0.685 respectively. 
All the results were statistically significant. According to multiple regression, attitudes and perceived behavioral control were statistically significant and the value could cover subjective norms, and therefore the hypothesis of $\mathrm{H} 1 \sim \mathrm{H} 3$ could not be rejected. ult, the tourists' attitudes, subjective norms and perceived behavioral control positively affect the intention of visit the paintings of Jingpu Colorful Village "Cat World". In particular, perceived behavioral control has great effect on tourists' intention than the attitudes toward the behavior and subjective norms.

\begin{tabular}{|c|c|c|c|c|}
\hline $\begin{array}{c}\text { Dependent } \\
\text { Variable }\end{array}$ & Intention & Intention & Intention & Intention \\
\hline \multicolumn{5}{|l|}{ Independent } \\
\hline & & & & \\
\hline Attitudes & $0.684^{\text {thH }}$ & & & $0.333^{* * *}$ \\
\hline Subjective Norms & & $0.543^{* *+*}$ & & 0.116 \\
\hline Perceived Behavioral Control & & & $0.685^{* * *}$ & $0.378^{* * *}$ \\
\hline $\mathrm{R}$ & 0.684 & 0.543 & 0.685 & 0.742 \\
\hline $\mathrm{R}^{2}$ & 0.468 & 0.295 & 0.470 & 0.550 \\
\hline adj. $\mathbb{R}^{2}$ & 0.466 & 0.292 & 0.467 & 0.543 \\
\hline F-value & 170.062 & 80.873 & 170.028 & 77.813 \\
\hline
\end{tabular}

Mediation effect of attitudes was examined with respect to criterion proposed by Baron and Kenny (1986). Compare the results given in model 2 and model 4 in Table 6 the standardized regression coefficient of subjective norms decreased from 0.543 to 0.169 , after adding attitudes in regression model. Attitudes still had significant positive effect on intention in model 4. As a result, the tourists' attitudes have a complete mediation effect on the relationships between subjective norms and intention. Hence, the hypothesis of $\mathrm{H} 4$ and $\mathrm{H} 6$ was not rejected.

Table 6. Mediation Effect Analysis (Mediator: Attitudes)

\begin{tabular}{lrrrr}
\hline Dependent Variable & Attitudes & Intention & Intention & Intention \\
Independent Variable & & & & \\
\hline Subjective norms & Model 1 & Model 2 & Model 3 & Model 4 \\
Attitudes & $0.652^{* * *}$ & $0.543^{* * *}$ & & 0.169 \\
$R$ & & & $0.684 * * *$ & $0.574^{* * *}$ \\
$R^{2}$ & 0.652 & 0.543 & 0.684 & 0.696 \\
adj . ${ }^{2}$ & 0.425 & 0.295 & 0.468 & 0.485 \\
F-value & 0.422 & 0.292 & 0.466 & 0.480 \\
\hline p $<0.05, * * p<0.01,{ }^{* * *} \mathrm{p}<0.001$ & 142.449 & 80.873 & 170.062 & 90.373 \\
\hline
\end{tabular}

Mediation effect of perceived behavioral control on the relationships between attitudes toward the behavior and intention. Compare the results given in model 2 and model 4in Table 7, the standardized regression coefficient of subjective norms decreased from0.543 to 0.235, after adding perceived behavioral control in regression model. Attitudes toward the behavior did not have a significant positive effect on intention in model 4. As a result, the perceived behavioral control has a partial mediation effect on the relationships between subjective norms and intention. Hence, the hypothesis of $\mathrm{H} 5$ andH7 was not rejected. 


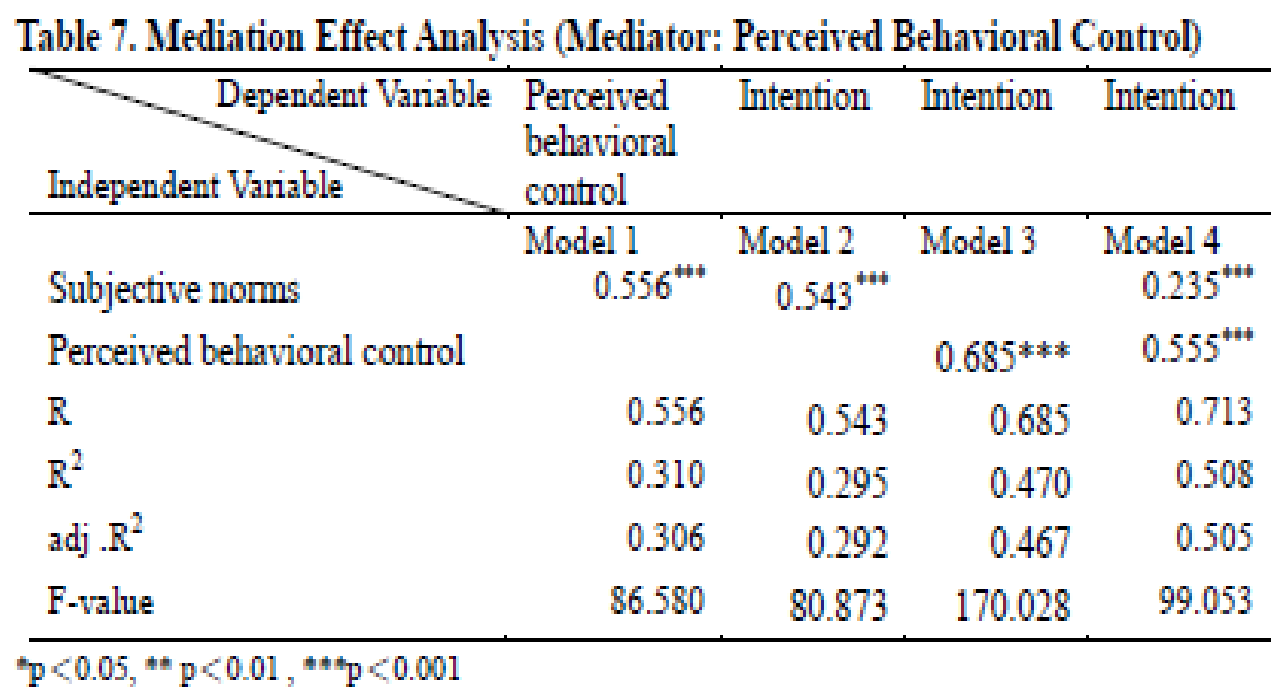

\section{Conclusions}

The results of regression analysis, factor analysis and reliability analysis in this study show that the standardized regression coefficient of each constructs to intention from the highest to the lowest were perceived behavioral control, attitudes, and subjective norms. The standardized regression coefficient was respectively given by 0.685 $0.684,0.543$, showing that the most important construct of influences on the tourists' intention to visit the Jingpu Colorful Village "Cat world" was perceived behavioral control. The tourists care more about their abilities such as time, health status, entrance fee and convenience of transportation. We could tell the tourists' cognition that visiting the painting village can increase the time being with family or friends, relieve the pressure in life, and that they were pleasant to stroll around due to well arrangement done by Jingpu Village Community Development Association. The construct of subjective norms indicated that friends and family would influence the tourists' intention to visit the Jingpu Colorful Village "Cat World". The interactive composition and contextual painting would make the tourists willing to take pictures and enhance the enjoyment in their tour. Furthermore the construct of subjective norms indicated that the reports by mass media and online referrals would influence tourists' intention to visit. The construct of intention showed that if the tourists were satisfied with this journey, they would be willing to visit again, to recommend the painting villages to their relatives and friends, to participate in related activities, and to recommend the tour destination on the internet. The suggestions from the important people, the reports by mass media and online referrals have positive influence on the tourists' willingness. However, most tourists will consider their ability to handle their time, health condition, financial ability, and transportation reasonably.

The results of two semi-structure questions showed that most of the tourists have visited other colorful villages in addition "Cat World", such as the paintings in Hao-Mei village, "Rainbow Village" in Taichung, "Tiptop Cat" in Yunlin and so on. In other words, tourists would like to visit colorful villages in case they are available. The suggestions to the Jingpu Village Community Development Association offered from the tourists indicated that improvement of hardware construction, including adding more toilets, parking lots, rest areas, guiding signs and so on is needed. In the future, the content of paintings combined with local industrial characteristics and the community conducting activities related to local industries could increase the depth and breadth of tourism, making tourists feel the visit being much more worthwhile.

Acknowledgements: The authors would like to thank all the participants. We thank a former director Gui-Duan Yang and Hui-Ting Yang for their assistances.

\section{References}

Ajzen, I. (1985). From intention to action: A theory of planned behavior. In J. Kuhl, \& J. Beckmann (Eds.), Action-control: From cognition to behavior (pp. 11-39). New York: Springer-Verlag

Ajzen, I., \& Madden, T. J. (1986). Prediction of goal directed behavior: Attitudes, intentions, and perceived behavioral control. Journal of Experimental Social Psychology, 22(5), 453-474 
Ajzen, I. (1991). The theory of planned behavior. Organizational Behavior and Human Decision Processes, 50, $179-211$.

Ajzen, I. (2006).Constructing a TpBQuestionnaire:Conceptual and Methodological Considerations. [Online] Available:https://pdfs.semanticscholar.org/0574/b20bd 58130dd5a961f1a2db10fd1fcbae95d.pdf (October 1, 2018)

Blackwell, R. D., Miniard, P.W., \& Engel J. F. (2012). Consumer behavior. Singapore: Cengage Learning Asia, (Chapter 8).

Baron, R. M., \& Kenny, D. A. (1986). The moderator-mediator variable distinction in social psychological research: Conceptual, strategic and statistical considerations. Journal of Personality and Social Psychology, 51(6), 1173-1182

Brady, M. K., \& Cronin, J. J. J. (2001). Customer orientation: Effects on customers service perceptions and outcome behaviors, Journal of Service Research, 3(3), 241.

Chang, L. Y. (2015). The Governance Predicament and Construction Strategies of Sustainable Community. The Degree of Doctor of Philosophy in Department Public Policy and Administration, National Chi Na University.

Chang, Y. C. (2012). Tourism Development in the Context of Community Empowerment: A Tourism Anthropological Analysis on the Fengtian Community in Hualien. The Degree of Doctor of Philosophy in Institute of Anthropological, Tsing- Hua University.

Chao, Chi-Ming, Huang, \& Wei-Ting (2015) Painted Research Community Loving Environment and Tourism Taking Huwei Township Top Brook Case. Journal of Cultural Enterprise and Management, 13, 57-72.

Dai, Y. U., Wang, C.T., Kao, S.Y., \& Lee, M. J. (2012) Behavior Study of Water Recreational Activities by Theory of Planned Behaviour - A Case in Penghu. Journal of Management Practices and Principles, 6(1), 33-58.

Department of Council for Cultural Affairs, Executive Yuan (2018). The White Paper on Cultural Affairs [Online] Available: http://mocfile.moc.gov.tw/mochistory/ images/policy/2004white_book/index.htm (March 26, 2018)

Hsieh, C. L. (2017) A Study on the Evaluation Model of Sustainable Management Strategy of Cultural. The Degree of Doctor of Philosophy in Management, College of Management, National Taipei University of Technology.

Hsieh, L. Y., Huang, C. Y., \& Hsu, M. C. (2017) Empirical Study on Tourist Behavioral Intentional Pattern of LiuDui Hakka Cultural Centre. Journal of Sport and Recreation Management, 14(2),1-12

Hsu, M. C., Yeh, M. J., \& Lin, Y. H. (2012) A Study on Tourists Traveling Behavior Intention Model in Dapeng Bay National Scenic Area- The Verification of Theory of Planned Behavior. Leisure \& Society Research, $6,1-25$.

Jingpu Community Development Association. (2018). Rural Regeneration Project of Jingpu Community, MingShung Township, Chiayi County. [Online]

Available: https://www.moi.gov.tw/chi/chi_site/stat/node.aspx?cate_sn=\&belong_sn=5992\&sn= 6026 (March 26, 2018)

Kim, D. J., Ferrin, D. L., \& Rao, H. R. (2009). Trust and satisfaction, two stepping stones for successful ecommerce relationships: A longitudinal exploration. Information Systems Research, 20(2), 237-257. DOI: 10.1287/isre.1080.0188

Kuo, C. J. (2008) The Study of Community Residents' Participation Behavior Model in Environmental Improvement Actions. The Degree of Doctor of Philosophy in Public Affairs Management, National Sun Yat-Sen University.

Ministry of Culture (2018), Community Taiwan [Online] Available: https://community taiwan.moc.gov.tw/ (September 27, 2018)

Schiffman, L. G., \&Kanuk, L. L. (2000). Consumer behavior (7th ed.). Upper Saddler River, NJ: Prentice Hall.

Taylor, S., \& Todd, P. (1995). Decomposition and crossover effects in the theory of planned behavior: A study of consumer adoption intentions. International Journal of Research in Marketing, 12(2), 137-155.

Wang, B. C. (2016) Discussing the Composition of the Cultural Life Circuit through the Local Development Process - A Case Study of Da-si Village, Miaoli County J o u r $n$ al o fArchi t ect u r e, 96 109-124

Zeithaml, V. A., Berry, L. L., \& Parasuraman, A. (1996). The behavioral consequences of service quality. Journal of Marketing, 60(2), 31-46. 